\title{
Individual differences in the motivation to communicate relate to levels of midbrain and striatal catecholamine markers in male European starlings
}

\author{
Sarah A Heimovics ${ }^{\mathrm{a}, 1}$, Katrina G Salvante ${ }^{\mathrm{b}, 2}$, Keith W Sockman ${ }^{\mathrm{b}, \mathrm{c}}$, and Lauren V Riters ${ }^{\mathrm{a},{ }^{*}}$ \\ aDept of Zoology, University of Wisconsin-Madison, Madison, WI, USA \\ ${ }^{b}$ Dept of Biology, University of North Carolina, Chapel Hill, NC USA \\ cCurriculum in Neurobiology, University of North Carolina, Chapel Hill, NC USA
}

\section{Abstract}

\begin{abstract}
Individuals display dramatic differences in social communication even within similar social contexts. Across vertebrates dopaminergic projections from the ventral tegmental area (VTA) and midbrain central gray (GCt) strongly influence motivated, reward-directed behaviors.

Norepinephrine is also rich in these areas and may alter dopamine neuronal activity. The present study was designed to provide insight into the roles of dopamine and norepinephrine in VTA and $\mathrm{GCt}$ and their efferent striatal target, song control region area $\mathrm{X}$, in the regulation of individual differences in the motivation to sing. We used high pressure liquid chromatography with electrochemical detection to measure dopamine, norepinephrine and their metabolites in micropunched samples from VTA, GCt, and area X in male European starlings (Sturnus vulgaris). We categorized males as sexually motivated or non-sexually motivated based on individual differences in song produced in response to a female. Dopamine markers and norepinephrine in VTA and dopamine in area X correlated positively with sexually-motivated song. Norepinephrine in area X correlated negatively with non-sexually-motivated song. Dopamine in GCt correlated negatively with sexually-motivated song, and the metabolite DOPAC correlated positively with non-sexually-motivated song. Results highlight a role for evolutionarily conserved dopaminergic projections from VTA to striatum in the motivation to communicate and highlight novel patterns of catecholamine activity in area X, VTA, and GCt associated with individual differences in sexually-motivated and non-sexually-motivated communication. Correlations between dopamine and norepinephrine markers also suggest that norepinephrine may contribute to individual differences in communication by modifying dopamine neuronal activity in VTA and GCt.
\end{abstract}

\section{Keywords}

dopamine; norepinephrine; communication; motivation; social context; courtship; song control system; social behavior; sexual behavior; songbird

\footnotetext{
() 2010 Published by Elsevier Inc.
}

*Corresponding author: Department of Zoology, 428 Birge Hall, 430 Lincoln Drive, University of Wisconsin, Madison, WI 53706; Phone: 608-262-6506; FAX: 608-265-6320; LVRiters@wisc.edu.

saheimovics@psych.ubc.ca, kgsalvan@sfu.ca,kws@unc.edu, LVRiters@wisc.edu

1 Present address: Dept of Psychology, University of British Columbia, Vancouver, BC, Canada

${ }^{2}$ Present address: Faculty of Health Sciences, Simon Fraser University, Burnaby, BC, Canada

Publisher's Disclaimer: This is a PDF file of an unedited manuscript that has been accepted for publication. As a service to our customers we are providing this early version of the manuscript. The manuscript will undergo copyediting, typesetting, and review of the resulting proof before it is published in its final citable form. Please note that during the production process errors may be discovered which could affect the content, and all legal disclaimers that apply to the journal pertain. 


\section{Introduction}

Vocal communication is central to successful social interactions, yet dramatic differences can be observed across individuals in the motivation to communicate even within similar social contexts. In male songbirds, song production plays a crucial role in mate attraction (Catchpole and Slater, 2008). Males with elevated concentrations of the steroid hormone testosterone respond to the introduction of a female conspecific with a dramatic increase in singing behavior; whereas males with low testosterone do not (Pinxten et al., 2002; Riters et al., 2000). Interestingly however even in males with similarly elevated concentrations of testosterone a subset of males fails to respond to females with an increase in singing and courtship behavior (e.g., (Goodson et al., 2009; Riters et al., 2000)). This suggests that interactions between steroid hormones and other neurochemical systems are likely critical for the production of male courtship song. Although aspects of vocal production in songbirds such as song learning, production, and sensorimotor processing have been relatively well studied (for recent reviews see (Ball et al., 2008; Brainard, 2008; Brenowitz, 2008; Gentner, 2008; Nordeen and Nordeen, 2008; Theunissen et al., 2008; Wild, 2008)), little is known about the neural basis of individual differences in the motivation to sing during conspecific interactions.

Across vertebrates, dopaminergic projections from the midbrain to striatal brain regions strongly influence multiple anticipatory, motivated, reward-directed behaviors (reviewed in (Berridge, 2007; Fibiger et al., 1992; Panksepp and Moskal, 2008; Schultz, 2010; Wise, 2005)), including sexually-motivated behaviors (e.g., (Hull et al., 1990; Pfaus et al., 1995)). In male songbirds, peripheral injections of an indirect dopamine receptor agonist (GBR-12909) stimulate, whereas antagonists (a D1/D2 antagonist cis-flupenthixol and a D1 antagonist SCH-23390) inhibit sexually-motivated, female-directed singing behavior (Rauceo et al., 2008; Schroeder and Riters, 2006). Tract-tracing studies identify the midbrain ventral tegmental area (VTA) and mesencephalic central gray (GCt) as primary sources of catecholaminergic inputs to song control regions, including area $\mathrm{X}$ of the avian striatum (Fig. 1) (Appeltants et al., 2000; Appeltants et al., 2002; Bottjer et al., 1989; Castelino et al., 2007; Lewis et al., 1981). In male European starlings immunolabeling for tyrosine hydroxylase (TH; the rate limiting enzyme for catecholamine synthesis) and autoradiography for dopamine receptors suggest that dopamine in VTA and GCt is more tightly coupled to sexually-motivated song compared to song produced in non-breeding condition males (Heimovics et al., 2009; Heimovics and Riters, 2008). The combined results of several additional studies in starlings and zebra finches using immunolabeling for immediate early genes (IEGs), IEG/TH double labeling, and electrophysiological recording also highlight roles for dopamine neurons in both VTA and GCt in the regulation of sexually-motivated male song production (Bharati and Goodson, 2006; Goodson et al., 2009; Hara et al., 2007; Heimovics and Riters, 2005; Yanagihara and Hessler, 2006).

Of the song control regions to which VTA and GCt project (Fig. 1), Area X shows among the most consistent and extreme differences in song-associated activity or gene expression across social contexts (e.g., (Hessler and Doupe, 1999; Jarvis et al., 1998; Riters et al., 2004; Teramitsu et al., 2010)). Area $\mathrm{X}$ is a component of the songbird basal ganglia circuit that underlies song learning and context-appropriate song variability in adults (Doupe et al., 2005; Leblois et al., 2010; Scharff and Nottebohm, 1991). Dopamine receptor stimulation influences neuronal activity in area X (Ding and Perkel, 2002; Ding et al., 2003); and dopamine levels in area $\mathrm{X}$ measured using microdialysis are higher during female-directed than undirected singing (Sasaki et al., 2006). Differential patterns of D1 and D2 receptor dopamine subtype colocalization with the IEG egr1 (referred to in birds by the acronym ZENK (Mello et al., 1992)) are also observed during directed and undirected singing in male 
zebra finches (Kubikova et al., 2010). Furthermore, pharmacological blockade of dopamine $\mathrm{D} 1$ receptors in area $\mathrm{X}$ disrupts context-dependent changes in song variability in male zebra finches singing female-directed compared to undirected song (Leblois et al., 2010).

Although VTA and GCt are sources of dopaminergic projections to area X (Fig. 1), both of these regions are also rich in noradrenergic alpha-2 receptors and the norepinephrine synthesizing enzyme dopamine beta hydroxylase (DBH; (Heimovics et al., 2011; Heimovics and Riters, 2008; Mello et al., 1998; Waterman and Harding, 2008)). DBH immunolabeled fibers in both GCt and VTA are found in close apposition to area X projecting neurons (Castelino et al., 2007). Past data demonstrate that norepinephrine depletion using the noradrenergic specific neurotoxin DSP-4 disrupts female-directed song production and reduces norepinephrine levels in area X (Barclay et al., 1996). DSP-4 also abolishes contextdependent differences observed in IEG activation in Area X associated with female-directed compared to undirected song (Castelino and Ball, 2005). These findings suggest that norepinephrine may modulate individual differences in sexually-motivated singing behavior by acting directly in area $\mathrm{X}$ or indirectly by acting in part on dopamine neurons within VTA and GCt.

In the present study we used high pressure liquid chromatography to examine levels of dopamine, norepinephrine, and their metabolites in micropunched samples from area X, VTA, and GCt in male European starlings (Sturnus vulgaris) singing in the presence of a female. Courtship in male starlings typically involves a male flying (often away from a female) to a nesting territory from which he produces high rates of song (rates above those observed when a female is not present (Eens, 1997; Riters et al., 2000)). Within a group of breeding condition male starlings however, some males respond to a female with a reduction in song production (e.g., (Heimovics et al., 2009; Heimovics and Riters, 2007; Riters et al., 2000)). Given that song in response to a female functions to attract mates (Eens et al., 1990; Eens et al., 1993), our assumption is that males that elevate song production in response to a female are sexually motivated. In contrast, we assume that males that reduce song in response to a female are less or non-sexually motivated (or perhaps sexually inhibited by competing males). The goal of the present study was to use these naturally occurring individual differences in the motivation to sing in male starlings to provide further insight into the role of catecholamines in the motivation to communicate.

\section{Material and Methods}

All protocols were approved by the University of Wisconsin Institutional Animal Care and Use Committee and adhered to methods approved by the National Institutes of Health Guide for the Care and Use of Laboratory Animals.

\section{Capture and housing}

We captured twenty four adult male and ten adult female starlings in November and December 2004 on a single farm northwest of Madison, WI using fly-in traps. Immediately after capture, we housed birds indoors in single sex cages $(91 \mathrm{~cm} \times 47 \mathrm{~cm} \times 47 \mathrm{~cm})$ in the University of Wisconsin-Madison Department of Zoology animal facilities on a light cycle mimicking the natural outdoor photoperiod. In January 2005, we shifted the photoperiod to 18L:6D for six weeks to render the birds photorefractory, a condition in which the hypothalamic-pituitary-gonadal (HPG) axis is insensitive to photoperiods with more than 11 $\mathrm{hr}$ light per 24-hr period (i.e., > 11L:13D) and gonads regress (Dawson et al., 2001). We then shifted the photoperiod to $6 \mathrm{~L}: 18 \mathrm{D}$ for six weeks to induce photosensitivity, a condition in which the HPG axis responds to photoperiods >11L:13D with gonadal recrudescence and increased circulating levels of steroid hormones (Dawson et al., 2001). Birds remained on 6L:18D until four weeks prior to behavioral observations when they were photoperiod and 
hormone manipulated to induce a breeding season-typical endocrine state and behavior (see next section).

\section{Hormone implants}

Four weeks prior to the first day of behavioral observations, we implanted males with subcutaneous (s.c.) testosterone (T) implants (two, 14mm lengths of silastic tubing [Dow Corning, inner diameter (i.d.): $1.47 \mathrm{~mm}$; outer diameter (o.d.): $1.96 \mathrm{~mm}$ ] packed for $10 \mathrm{~mm}$ with crystalline testosterone proprionate and sealed with silastic glue [Sigma]). We implanted females with implants of estradiol $\left(\mathrm{E}_{2} ;\right.$ two, $17 \mathrm{~mm}$ lengths of silastic tubing packed for $13 \mathrm{~mm}$ with $17 \beta$-estradiol sealed and with silastic glue [Sigma]). $\mathrm{T}$ and $\mathrm{E}_{2}$ implants were used because past studies in our lab indicate that in captivity, un-implanted birds are slow to exhibit the full suite of behaviors typical of the breeding season. Past data using this treatment in a separate group of males resulted in T concentrations of $1539.96 \mathrm{pg} /$ $\mathrm{ml}, \mathrm{sd}=711.68, \mathrm{n}=17$ (Heimovics et al., 2011), which is within the physiological range observed in studies of wild caught starlings during the breeding season (Dawson, 1983; Riters et al., 2002). For implant surgery, we lightly anesthetized each bird using isoflurane gas anesthesia, and made a small incision in the skin just posterior to the last rib on the left side. We inserted implants under the skin, sutured the incision, and allowed birds to recover on a heated pad. After recovery, we assigned each bird a unique combination of colored leg bands (for individual recognition), placed them back into single-sex cages, and shifted to them to a photoperiod of 11L:13D.

\section{Behavioral observations}

Two weeks after T-implant surgery, we placed males into two separate outdoor aviaries $(3.7 \mathrm{~m} \times 2 \mathrm{~m} \times 2.8 \mathrm{~m})$ in two social groups of twelve birds each. The outdoor aviary contained seven nestboxes, branches for perching, food, and water. Males habituated to the aviaries for 2 weeks prior to initiation of behavioral observations. We behaviorally tested birds in social groups because we were interested in examining individual variation in singing behavior as it occurs within a dynamic social system. We observed social groups for one hour a day for five days over the course of one week. Each hour-long behavioral observation period consisted of thirty minutes with a female present in the aviary and thirty minutes without a female present in the aviary. We counterbalanced the order of each thirty minute session across days, and used a novel female each day. We used a point sampling technique (Eens et al., 1990) to quantify song. Specifically, during each thirty minute period we noted at sixty second intervals if any member of the social group was singing. We used these five days of behavioral observations to estimate the proportion of time each male spent singing both in the absence and the presence of a female. All observations took place between 0900 and 1200 , and the outdoor photoperiod ranged from 14L:10D to 15L:9D across the entire length of the experiment. Behavioral data analyses are detailed below in the Data Analysis section.

\section{Tissue Processing}

One day after the last day of behavioral observations, we sacrificed males using rapid decapitation. Brains were removed, snap frozen in isopentane on dry ice, and stored at $-80^{\circ} \mathrm{C}$ until sectioning. We verified the presence of T-implants at this time, and all males had implants with some $\mathrm{T}$ remaining. We sectioned brains using a cryostat set to $-10^{\circ} \mathrm{C}$ in the coronal plane into $300 \mu \mathrm{m}$-thick sections. We identified sections containing area X, VTA, and GCt using landmarks and a songbird brain atlas (Stokes et al., 1974). We selected these areas based on our interest in dopamine and motivation and existing literature reviewed in the introduction. We collected micropunched samples of each brain region using a sample corer (Fine Science Tools, Foster City, CA). For Area X we used a sample corer with an o.d. of $3 \mathrm{~mm}$ and i.d. of $2 \mathrm{~mm}$. For GCt and VTA, we used a sample corer with an o.d. of $1.8 \mathrm{~mm}$ and i.d. of 1mm. We collected punches bilaterally from Area X and VTA (Fig. 2) and a 
single punch, centered on the midline, from GCt (Fig. 2). We expelled punches into a microcentrifuge tube cooled to $-10^{\circ} \mathrm{C}$ inside of the cryostat. Microcentrifuge tubes were subsequently placed on dry ice until all punches from one brain were collected, and then stored at $-80^{\circ} \mathrm{C}$ until assay.

\section{Quantification of Monoamine Metabolites and Protein}

When monoamines are secreted into the synapse, enzymes metabolize them. Thus, as indices of monoamine secretion, we quantified levels of their principal metabolites (Moore, 1986). Using previously described protocols (Sockman and Salvante, 2008), we measured tissue concentrations of dopamine and the dopamine metabolites 3,4-dihydroxyphenylacetic acid (DOPAC) and homovanillic acid (HVA), and norepinephrine and the norepinephrine metabolite 3-methoxy-4-hydroxy-phenylglycol (MHPG) using reversed-phase high-pressure liquid chromatography (HPLC) with electrochemical detection (Kilts et al., 1981). Briefly, we separated compounds using a Monochrom C18 $3 \mu \mathrm{m}$ column $(100 \times 4.6 \mathrm{~mm}$, MetaChem) with a mobile phase $(1 \mathrm{~L}, \mathrm{pH} 3.5)$ consisting of sodium phosphate $(7.1 \mathrm{~g})$, citric acid $(5.76 \mathrm{~g})$, disodium EDTA $(50 \mathrm{mg})$, sodium octyl sulfonate $(400 \mathrm{mg}$ ) and methanol $(13 \%)$. We maintained electrode potential at $650 \mathrm{mV}$ with respect to an $\mathrm{Ag} / \mathrm{AgCl}$ reference electrode. We prepared standard solutions containing a fixed amount (30 $\mathrm{ng}$ ) of the internal standard (isoproterenol, Sigma) and variable amounts of each monoamine and their metabolites. We included a five-point standard curve in each assay $(5 \times 50 \mu \mathrm{L}$ injections), and used linear regression to fit a line through the standard curve points $\left(R^{2}>0.99\right.$ for each of the components in each assay).

The HPLC assay was run on single samples. Immediately before assay we added mobile phase $(225 \mu \mathrm{l})$ containing $30 \mathrm{ng}$ isoproterenol to each tube. We sonicated the samples and then centrifuged them at $16,000 \mathrm{~g}$ for 15 minutes at $4^{\circ} \mathrm{C}$. We aspirated the supernatant and injected $50 \mu \mathrm{l}$ from each sample into the HPLC system. We calculated the monoamine and metabolite contents by first correcting their peak heights for percent recovery of the internal standard (i.e., the height of the isoproterenol peak) for each sample and then compared the values to those obtained for the corresponding monoamine and metabolites in the standard curve.

We measured the protein content of each sample by dissolving the remaining sample pellet in $100 \mu \mathrm{l} 0.2 \mathrm{~N} \mathrm{NaOH}$ and performing the Bradford protein-dye binding assay (Quick Start Bradford Protein Assay, Bio-Rad) with bovine serum albumin (Bio-Rad) as a standard on a $\mu$ Quant microplate spectrophotometer (BioTek) (Bradford, 1976).

\section{Data analysis}

We summed the point-sampled singing behavior in the presence of a female across the 5 days of behavioral observation. We also summed the point-sampled singing behavior in the absence of a female across the 5 days of observation. Because data were expressed as a proportion (number of point samples with song out of 150 (i.e. 5 days with 30 possible point samples each day)), the sums were then arcsine transformed to improve normality using the following equation: $2 \times$ arcsine $\sqrt{ }(\#$ observed songs/150) (as recommended by Lehner (Lehner, 1996)). Males that produced $50 \%$ or more of their total song in the presence of a female were assigned to the sexually-motivated group. Males that sang less than $50 \%$ of their total song in the presence of a female (that is males that sang most of their song when no female was present) were assigned to the non-sexually-motivated group. (These groups are similar to courting and non-courting phenotypes identified in zebra finches by Goodson and collaborators (Goodson et al., 2009)). We corrected concentrations of dopamine, norepinephrine, DOPAC, HVA, and MHPG for total level of protein in the punch expressed as picograms (pg) per milligram $(\mathrm{mg})$ of protein. Data were analyzed using Statistica 6.0 
software (Stat Soft, Inc., Tulsa, OK, USA). We ran repeated measures ANOVAs to examine the mean number of minutes across the 5 test days at which males were singing with and without a female present entered as a repeated measures variable and male group (sexuallyand non-sexually-motivated) as a between subjects variable. We ran separate Pearson correlation analyses to examine the relationship between song in response to a female in sexually-motivated and non-sexually-motivated males and dopamine, DOPAC, HVA, norepinephrine, and MHPG in each brain region. When significant correlations were identified, we followed the correlation analyses with a homogeneity of slopes multiple regression analysis to determine whether the slopes of the relationships between song and catecholamine markers differed between males in the sexually-motivated and non-sexuallymotivated groups. If data did not meet the assumptions of parametric statistics, they were $\log$ transformed. In all cases, log transformed data met the assumptions of parametric statistics. $\mathrm{p}<0.05$ was considered statistically significant.

We performed multiple regression analyses to provide insight into the possibility that norepinephrine activity modulates dopamine activity within VTA and GCt (as suggested by (Castelino et al., 2007)). For these analyses, dopaminergic measures were entered as dependent variables. Specifically, for GCt and VTA, 3 analyses were run, one with dopamine, one with DOPAC, and one with HVA entered as the dependent variable. For each analysis measures of norepinephrine and MHPG and the group to which a male was assigned (sexually-or non-sexually-motivated) were entered as predictor variables. For multiple regression analysis of VTA results of both forward and backward analyses were identical. For analysis of GCt DOPAC and HVA numerical results differed slightly but significant contributors were identical and the best model based on overall adjusted $\mathrm{R}^{2}$, residual plots, and the standard error is reported (results of the forward regression in all cases). Individuals identified as statistical outliers (i.e., individuals with standardized residuals $>2$ times the standard deviation of residuals) were identified and results are reported without these individuals when they substantially weakened the models (based on overall adjusted $\mathrm{R}^{2}$, residual plots, and the standard error). This was only the case for GCt dopamine and GCt DOPAC (detailed in results).

We ran additional multiple regression analyses to provide insight into the extent to which dopamine in VTA and GCt influences catecholamine activity in area X (a major efferent projection for these regions; Fig. 1). For these analyses, each of the 5 catecholamine markers in area $\mathrm{X}$ was entered as a dependent variable in separate analyses. For each analysis the dopamine measures for VTA and GCt were entered as predictor variables. (These measures were not correlated.) Significant results of both forward and backward analyses were identical, and no outliers were identified.

\section{Results}

\section{Sexually-motivated and non-sexually-motivated males}

Fourteen males produced greater than $50 \%$ of their total song when a female was present compared to when no female was present and were assigned to the sexually-motivated group. Ten males produced greater than $50 \%$ of total song when a female was absent compared to when a female was present and were assigned to the non-sexually-motivated group. A repeated measures ANOVA revealed a significant interaction $\left(\mathrm{F}_{1,22}=33.49, \mathrm{p}=\right.$ 0.000008 ; Fig. $3 \mathrm{~A}$ and $\mathrm{B}$ ) but no significant main effects for singing behavior in the presence compared to the absence of a female in sexually-compared to non-sexuallymotivated males. Post hoc Fisher's LSD tests indicated that sexually-motivated males significantly increased singing behavior in response to a female $(\mathrm{p}=0.00001)$; whereas, non-sexually-motivated males reduced singing behavior in response to a female $(p=0.01$; Fig. 3A and B). 
Paired comparisons revealed no statistically significant differences between sexuallymotivated or non-sexually-motivated males for any catecholamine marker, and these between subjects comparisons will not be discussed further. For all analyses differences in sample sizes reflect missing data due to tissue damage or cases in which detectable peaks for a particular monoamine or metabolite were not identified (indicating a problem with that measure).

Although behavior varied along a continuum (Fig. 3), significant correlations were identified between song in response to a female and catecholamine markers in distinct brain regions only when males were categorized as sexually or non sexually motivated (results presented below). Correlations were not significant when males from the two groups were combined, although trends were observed for VTA MHPG $(r=0.43, p=0.06)$, GCt dopamine $(r=$ $-0.40, p=0.06)$, and GCt MHPG $(r=0.38, p=0.07 ; p>0.18$ for all other correlations $)$.

\section{VTA dopamine markers}

Dopamine, DOPAC, and HVA in VTA correlated positively with song produced in the presence of a female in sexually-motivated males (dopamine: $r=0.64, p=0.017$; DOPAC: $r$ $=0.61, \mathrm{p}=0.026 ;$ HVA: $\mathrm{r}=0.56, \mathrm{p}=0.045)$ but not non-sexually-motivated males (dopamine: $\mathrm{r}=-0.46, \mathrm{p}=0.301$; DOPAC: $\mathrm{r}=-0.15, \mathrm{p}=0.742$; HVA: $\mathrm{r}=-0.27, \mathrm{p}=0.558$; Fig. 4A-C). Homogeneity of slopes multiple regression analyses indicated that the slopes differed significantly between the two groups for dopamine $(\mathrm{p}=0.03)$ but not DOPAC $(\mathrm{p}=$ $0.229)$ or HVA $(\mathrm{p}=0.148)$.

\section{VTA norepinephrine markers}

Norepinephrine in VTA correlated positively with song in the presence of a female in sexually-motivated males $(r=0.60, p=0.031)$. A non-significant trend was identified for norepinephrine in VTA to correlate negatively with song in non-sexually-motivated males ( $\mathrm{r}$ $=-0.74, p=0.058 ;$ Fig. 4D). A homogeneity of slopes multiple regression analysis indicated that the slopes differed significantly between the two groups $(p=0.003)$. No significant correlations between song and MHPG in VTA were identified in either sexuallymotivated or non-sexually-motivated males ( $p>0.18$ for all correlations; Fig. 4E).

\section{Contributions of norepinephrine and MHPG to dopamine markers in VTA}

Results of 3 separate multiple linear regression analyses revealed significant contributions of both VTA norepinephrine and VTA MHPG concentrations to VTA dopamine, a significant contribution of VTA norepinephrine concentrations to VTA DOPAC, and a significant contribution of VTA norepinephrine and VTA MHPG concentrations to VTA HVA (statistical results presented in Table 1).

\section{GCt dopamine markers}

Dopamine in GCt correlated negatively with song in the presence of a female in sexuallymotivated males $(\mathrm{r}=-0.67, \mathrm{p}=0.017)$ but not non-sexually-motivated males $(\mathrm{r}=-0.36, \mathrm{p}=$ 0.304; Fig. 5A). In contrast, DOPAC in GCt correlated positively with song in non-sexuallymotivated males $(r=0.76, p=0.030)$ but not sexually-motivated males $(r=0.12, p=0.710$; Fig. 5B). A homogeneity of slopes multiple regression analysis indicated that the slopes did not differ significantly between the two groups for dopamine $(p=0.740)$ but they did differ significantly for DOPAC $(\mathrm{p}=0.042)$. No significant correlations were identified between song and HVA in GCt for either sexually-motivated or non-sexually-motivated males ( $\mathrm{p}$ > 0.50 for all correlations; Fig. 5C). 


\section{GCt norepinephrine markers}

No significant correlations were identified between song in the presence of a female for either sexually-motivated or non-sexually-motivated males and norepinephrine or MHPG in GCt $\mathrm{p}>0.16$ for all correlations; Fig. 5D and E).

\section{Contributions of norepinephrine and MHPG to dopamine markers in GCt}

Results of 3 separate multiple linear regression analyses revealed a significant contribution of GCt norepinephrine concentrations to GCt dopamine, a significant contribution of GCt norepinephrine concentrations to GCt DOPAC, and a significant contribution of GCt MHPG concentrations to GCt HVA (statistical results presented in Table 1). One outlier was removed from the analysis of GCt dopamine and one from the analysis of GCt DOPAC (based on criteria detailed in the Data Analysis section). When these outliers were included, models were not significant ( $\mathrm{p}=0.14$ and 0.09 , respectively).

\section{Area $\mathrm{X}$ dopamine markers}

Dopamine in area $\mathrm{X}$ correlated positively with song in the presence of a female in sexuallymotivated males $(r=0.68, p=0.015)$ but not non-sexually-motivated males $(r=-0.08, p=$ 0.839 ; Fig. 6A). However, a homogeneity of slopes multiple regression analysis indicated that the slopes did not differ significantly between the two groups $(p=0.25)$. No significant correlations between song and DOPAC or HVA in area X were identified for sexuallymotivated or non-sexually-motivated males ( $p>0.24$ for all correlations; Fig. 6 B and C).

\section{Area $\mathrm{X}$ norepinephrine markers}

In contrast to dopamine, norepinephrine in area $\mathrm{X}$ did not correlate with song in the presence of a female in sexually-motivated males $(r=0.20, p=0.536)$ but correlated negatively with song in non-sexually-motivated males $(r=-0.71, p=0.031$; Fig. 6D). A homogeneity of slopes multiple regression analysis indicated that the slopes differed significantly between the two groups $(\mathrm{p}=0.022)$. No significant correlations were identified between song and MHPG in area X for males singing either sexually-motivated or non-sexually-motivated song ( $p>0.70$ for all correlations; Fig. 6E).

\section{Contributions of dopamine in VTA and GCt to markers in area $\mathbf{X}$}

Results of 5 separate multiple linear regression analyses revealed a significant contribution of VTA dopamine concentrations to area $\mathrm{X}$ dopamine and significant contributions for both VTA and GCt dopamine concentrations to area X DOPAC (statistical results presented in Table 2). Dopamine in VTA and GCt did not contribute significantly to variance in any other marker.

\section{Discussion}

Little is known about the neural regulation of the motivation to communicate in any vertebrate species. In male songbirds the steroid hormone testosterone clearly plays a role in sexually-motivated-song production (Ball et al., 2004; Pinxten et al., 2002; Riters et al., 2000), yet as observed in the present and past studies (e.g., (Heimovics et al., 2009; Heimovics and Riters, 2007; Riters et al., 2000)) even with similarly high testosterone concentrations some males do not sing in response to females. This suggests that neurochemical systems in addition to testosterone must contribute to the production of sexually-motivated-male song. Given the role of midbrain dopaminergic projections to striatal brain regions in a variety of anticipatory, reward-directed, motivated behaviors (reviewed in (Berridge, 2007; Fibiger et al., 1992; Panksepp and Moskal, 2008; Schultz, 2010; Wise, 2005)), we predicted that variation in dopamine activity in VTA and GCt and 
their efferent striatal target, area $\mathrm{X}$ would be associated with individual variation in vocal production. The present results support this idea, highlighting distinct patterns of catecholamine activity within area X, VTA, and GCt in association with the propensity of subgroups of males to produce sexually-motivated and non-sexually-motivated song.

In the present study males assigned to the sexually-motivated and non-sexually-motivated groups sang at similarly high rates; however they differed substantially in the amount of song they produced in response to a female. Males assigned to the sexually-motivated group significantly increased song production in response to a female; whereas males assigned to the non-sexually-motivated group showed a reduction in song output in the presence of a female. A primary function of male starling song in the breeding season is mate attraction (Eens et al., 1990; Eens et al., 1993), thus we consider the differences in the context in which males preferentially sing to reflect distinct differences in the motivational state of birds in the two groups. Although singing behavior varied along a continuum significant correlations were only observed between singing and catecholamine markers in specific brain regions when males were categorized by group, further indicating that males in these groups belong to distinct subpopulations.

\section{Dopamine markers in area $X$ and VTA correlated positively with sexually-motivated song}

Dopamine concentrations in Area X and VTA as well as dopamine metabolites in VTA correlated positively only with sexually-motivated song. These findings are similar to recent data from our laboratory in male starlings showing that the density of TH in VTA and Area $\mathrm{X}$ correlated exclusively with sexually-motivated song and not song produced in flocks of non-breeding condition males (Heimovics and Riters, 2008). These correlations were not observed for the noradrenergic marker dopamine beta hydroxylase, suggesting they reflected dopamine innervation. The present results also parallel work in male zebra finches showing that numbers of VTA neurons double labeled for TH and Fos correlate with courtship song production (Goodson et al., 2009). Past studies also demonstrate that the activity of dopaminergic neurons in VTA (Yanagihara and Hessler, 2006) and dopamine concentrations in Area X (Sasaki et al., 2006) are elevated during female-directed, sexually-motivated song and low during undirected song. Patterns of D1 and D2 receptor colocalization with egr1 expression are also consistent with lower dopamine release in area $\mathrm{X}$ during undirected song (Kubikova et al., 2010).

In songbirds, tract-tracing studies identify VTA as a source of dopaminergic input to Area X (Fig. 1) (Bottjer et al., 1989; Lewis et al., 1981), and female-directed singing behavior can be considered a reflection of sexual incentive motivation. Thus, the present data taken together with past work highlight dopamine acting within the VTA $\rightarrow$ Area $X$ neural circuit as an important modulator of sexual, incentively-motivated vocal communication. Past data suggest the VTA may play a role in the motivation to engage in directed communication across contexts and species. For example, correlations have been found between IEG labeling in VTA and agonistically-motivated male song directed towards another male (Maney and Ball, 2003), and in rats both dopamine neuron specific lesions in VTA and dopamine antagonists injected into the VTA selectively reduced vocalizations produced in anticipation of social interaction (Burgdorf et al., 2007).

\section{Norepinephrine in VTA correlated positively with sexually-motivated song}

Norepinephrine in VTA also correlated positively with sexually-motivated song. The role of norepinephrine in VTA in sexually-motivated song or other sexually-motivated behaviors has not been well-characterized. In rats, norepinephrine can alter firing of dopamine neurons in VTA (Arencibia-Albite et al., 2007; Grenhoff and Svensson, 1989; Grenhoff and Svensson, 1993; Guiard et al., 2008). Thus cross-talk between dopamine and norepinephrine 
in the VTA may fine-tune sexually-motivated song. This idea is supported by the significant contribution of both norepinephrine and MHPG to variance in dopamine and its metabolites in VTA detected in the present study.

\section{Norepinephrine in area $\mathrm{X}$ correlated negatively with non-sexually-motivated song}

The negative correlation found between non-sexually-motivated song and norepinephrine in area $\mathrm{X}$ is consistent with past data in male starlings demonstrating negative correlations between norepinephrine concentrations in area $\mathrm{X}$ and song rate (as well as song bout length) by males singing alone (i.e., males singing undirected, non-sexually-motivated song; (Salvante et al., 2010)). We additionally observed a trend $(\mathrm{p}=0.058)$ for norepinephrine in VTA to correlate negatively with non-sexually-motivated song, which should be examined in future research. Past data show that DSP-4 depletion of noradrenergic neurons increases IEG expression in area X during directed singing (Castelino and Ball, 2005), and studies show that activity in VTA dopamine neurons can be suppressed by norepinephrine (e.g., (Guiard et al., 2008)). It is thus possible that the negative correlations between song rate and norepinephrine in area X and possibly VTA observed here reflect an inhibitory role for norepinephrine in these regions on non-sexually-motivated singing behavior.

\section{Dopamine markers in GCt correlated with sexually- and non-sexually-motivated song}

For males singing sexually-motivated song a negative correlation was found between song and dopamine concentrations in GCt. This finding is consistent with a past study in male starlings showing a negative correlation between sexually-motivated song and D1 dopamine receptors in GCt (Heimovics et al., 2009). This suggests that dopamine activity in GCt may play an inhibitory role in sexually-motivated song behavior; however, given that HPLC measures in micropunched tissues do not provide insight into whether dopamine is stored or used, it is also possible that dopamine activity is elevated in males singing at high rates to females and that the lower concentrations of dopamine reflect increased use. Indeed in male zebra finches the numbers of TH/IEG double labeled cells in GCt correlated positively with sexually-motivated song (Goodson et al., 2009). Given the limitations of correlational studies using dopamine markers, whether dopamine in GCt serves to stimulate or inhibit female-directed song must be examined using measures of release or site-specific manipulations in future work.

For males singing non-sexually-motivated song, a positive correlation was found between song and DOPAC in GCt. It is possible that increased DOPAC reflects increased dopamine use, which may be reflected in the trend for a negative correlation between song rate and dopamine concentrations (i.e., as dopamine is used, it may be depleted). However, why the same patterns would not be observed for dopamine and its metabolites in GCt or VTA associated with sexually-motivated song is not clear. Site-specific manipulations of dopamine or measures of dopamine release using microdialysis are needed to more fully interpret the functional significance of the directions of relationships observed in this study. Finally, the finding that dopamine markers in GCt correlate with both sexually- and nonsexually-motivated song suggest a role for this region in vocal behavior across social contexts. This idea is supported by past studies implicating GCt in agonistically-motivated song in response to conspecific males (Heimovics et al., 2009; Maney and Ball, 2003) and activity in TH positive cells in GCt in undirected song (Lynch et al., 2008).

\section{Evidence that dopamine and norepinephrine may interact in VTA and GCt to regulate song}

To provide some insight into the possibility that norepinephrine acts locally within VTA and GCt to modify activity in dopamine neurons, we statistically examined the extent to which norepinephrine and MHPG explained variance in dopamine markers within each nucleus using multiple regression analyses. Variation in norepinephrine markers substantially 
contributed to variance in dopamine markers in both VTA and GCt. Both VTA and GCt send dopaminergic projections to area X (Fig. 1) (Bottjer et al., 1989; Lewis et al., 1981), and DBH positive neurons are in close apposition to area $\mathrm{X}$ projecting neurons in these regions (Castelino et al., 2007). Multiple studies in rodents demonstrate that norepinephrine modulates activity in VTA dopamine neurons through alpha- 1 and alpha-2 norepinephrine receptors as well as dopamine receptors (Arencibia-Albite et al., 2007; Grenhoff and Svensson, 1989; Grenhoff and Svensson, 1993; Guiard et al., 2008). Dopamine also binds to norepinephrine receptors in birds and mammals (Cornil and Ball, 2008). The correlations between norepinephrine and dopamine markers in GCt and VTA found here further suggest interactions between the two catecholamines in modulating context-dependent vocal production.

\section{Dopamine in VTA and GCt correlates with dopamine markers in area X}

Multiple regression analysis revealed positive correlations between dopamine concentrations in VTA and dopamine concentrations in area X, consistent with prior studies demonstrating a strong dopaminergic projection from VTA to area X (Bottjer et al., 1989; Lewis et al., 1981). In contrast, dopamine concentrations in both VTA and GCt related negatively to DOPAC concentrations in area X. The low concentrations of dopamine in VTA and GCt found in association with high concentrations of the dopamine metabolite DOPAC in area X may reflect the use of dopamine received from VTA and GCt projection to area X.

\section{Conclusions}

The results of this study indicate that naturally occurring individual variation in the motivation to sing in response to a female is reflected in catecholamine activity in projections from midbrain dopaminergic brain regions to the striatum. Midbrain dopamine systems are central for the production of multiple incentively-motivated, reward-directed behaviors. The present results suggest that the evolutionarily conserved role for dopamine projections from VTA to the striatum in motivated behavior also extends to the motivation to communicate, and that norepinephrine may modulate individual differences in singing behavior by acting directly in area $\mathrm{X}$ or by modifying activity in dopamine neurons in VTA and GCt.

\section{Acknowledgments}

The data presented in this paper are based upon work supported by grants from NIH to LVR (R01 MH080225) and KWS (R01 NS055125) and a graduate research fellowship from NSF to SAH. We gratefully acknowledge Kate Skogen, Jeff Alexander, Chris Elliot, and John Irwin for help with starling capture and animal care and Bill Feeny for assistance with illustrations. We thank Dr. Richard B. Mailman and Stan B. Southerland for providing and helping with the HPLC system in Chapel Hill.

\section{References}

Appeltants D, Absil P, Balthazart J, Ball GF. Identification of the origin of catecholaminergic inputs to $\mathrm{HVc}$ in canaries by retrograde tract tracing combined with tyrosine hydroxylase immunocytochemistry. J Chem Neuroanat. 2000; 18:117-133. [PubMed: 10720795]

Appeltants D, Ball GF, Balthazart J. The origin of catecholaminergic inputs to the song control nucleus RA in canaries. Neuroreport. 2002; 13:649-653. [PubMed: 11973464]

Arencibia-Albite F, Paladini C, Williams JT, Jimenez-Rivera CA. Noradrenergic modulation of the hyperpolarization-activated cation current (Ih) in dopamine neurons of the ventral tegmental area. Neuroscience. 2007; 149:303-314. [PubMed: 17884297]

Ball GF, Auger CJ, Bernard DJ, Charlier TD, Sartor JJ, Riters LV, Balthazart J. Seasonal plasticity in the song control system: multiple brain sites of steroid hormone action and the importance of variation in song behavior. Ann N Y Acad Sci. 2004; 1016:586-610. [PubMed: 15313796] 
Ball, GF.; Riters, LV.; MacDougall-Shackleton, SA.; Balthazart, J. Sex differences in brain and behavior and the neuroendocrine control of the motivation to sing. In: Ziegler, HP.; Marler, PR., editors. Neuroscience of Birdsong. Cambridge University Press; Cambridge: 2008. p. 320-331.

Barclay SR, Harding CF, Waterman SA. Central DSP-4 treatment decreases norepinephrine levels and courtship behavior in male zebra finches. Pharmacol Biochem Behav. 1996; 53:213-220. [PubMed: 8848453]

Berridge KC. The debate over dopamine's role in reward: the case for incentive salience. Psychopharmacology (Berl). 2007; 191:391-431. [PubMed: 17072591]

Bharati IS, Goodson JL. Fos responses of dopamine neurons to sociosexual stimuli in male zebra finches. Neuroscience. 2006; 143:661-670. [PubMed: 17027163]

Bottjer SW, Halsema KA, Brown SA, Miesner EA. Axonal connections of a forebrain nucleus involved with vocal learning in zebra finches. J Comp Neurol. 1989; 279:312-326. [PubMed: 2464011]

Bradford MM. A rapid and sensitive method for the quantitation of microgram quantities of protein utilizing the principle of protein-dye binding. Anal Biochem. 1976; 72:248-254. [PubMed: 942051]

Brainard, MS. The anterior forebrain pathway and vocal plasticity. In: Ziegler, HP.; Marler, PR., editors. Neuroscience of Birdsong. Cambridge University Press; Cambridge: 2008. p. 240-255.

Brenowitz, EA. Plasticity of the song control system in adult birds. In: Ziegler, HP.; Marler, PR., editors. Neuroscience of Birdsong. Cambridge University Press; Cambridge: 2008. p. 332-349.

Burgdorf J, Wood PL, Kroes RA, Moskal JR, Panksepp J. Neurobiology of 50-kHz ultrasonic vocalizations in rats: electrode mapping, lesion, and pharmacology studies. Behav Brain Res. 2007; 182:274-283. [PubMed: 17449117]

Castelino CB, Ball GF. A role for norepinephrine in the regulation of context-dependent ZENK expression in male zebra finches (Taeniopygia guttata). Eur J Neurosci. 2005; 21:1962-1972. [PubMed: 15869489]

Castelino CB, Diekamp B, Ball GF. Noradrenergic projections to the song control nucleus area X of the medial striatum in male zebra finches (Taeniopygia guttata). J Comp Neurol. 2007; 502:544562. [PubMed: 17394158]

Catchpole, CK.; Slater, PJB. Bird song : biological themes and variations. Cambridge University Press; Cambridge, [England]: 2008.

Cornil CA, Ball GF. Interplay among catecholamine systems: dopamine binds to alpha2-adrenergic receptors in birds and mammals. J Comp Neurol. 2008; 511:610-627. [PubMed: 18924139]

Dawson A. Plasma gonadal steroid levels in wild starlings (Sturnus vulgaris) during the annual cycle and in relation to the stages of breeding. Gen Comp Endocrinol. 1983; 49:286-294. [PubMed: 6840523]

Dawson A, King VM, Bentley GE, Ball GF. Photoperiodic control of seasonality in birds. J Biol Rhythms. 2001; 16:365-380. [PubMed: 11506381]

Ding L, Perkel DJ. Dopamine modulates excitability of spiny neurons in the avian basal ganglia. J Neurosci. 2002; 22:5210-5218. [PubMed: 12077216]

Ding L, Perkel DJ, Farries MA. Presynaptic depression of glutamatergic synaptic transmission by D1like dopamine receptor activation in the avian basal ganglia. J Neurosci. 2003; 23:6086-6095. [PubMed: 12853427]

Doupe AJ, Perkel DJ, Reiner A, Stern EA. Birdbrains could teach basal ganglia research a new song. Trends Neurosci. 2005; 28:353-363. [PubMed: 15935486]

Eens M. Understanding the complex song of the European starling: An integrated approach. Adv Study Beh. 1997; 26:355-434.

Eens M, Pinxten R, Verheyen RF. On the function of singing and wing-waving in the European starling Sturnus vulgaris. Bird Study. 1990; 37:48-52.

Eens M, Pinxten R, Verheyen RF. Function of the song and song repertoire in the European starling (Sturnus vulgaris): An aviary experiment. Behaviour. 1993; 125:51-66.

Fibiger HC, Nomikos GG, Pfaus JG, Damsma G. Sexual behavior, eating and mesolimbic dopamine. Clin Neuropharmacol. 1992; 15(Suppl 1 Pt A):566A-567A. 
Gentner, TQ. Temporal auditory pattern recognition in songbirds. In: Ziegler, HP.; Marler, PR., editors. Neuroscience of Birdsong. Cambridge University Press; Cambridge: 2008. p. 187-198.

Goodson JL, Kabelik D, Kelly AM, Rinaldi J, Klatt JD. Midbrain dopamine neurons reflect affiliation phenotypes in finches and are tightly coupled to courtship. Proc Natl Acad Sci U S A. 2009; 106:8737-8742. [PubMed: 19439662]

Grenhoff J, Svensson TH. Clonidine modulates dopamine cell firing in rat ventral tegmental area. Eur J Pharmacol. 1989; 165:11-18. [PubMed: 2569981]

Grenhoff J, Svensson TH. Prazosin modulates the firing pattern of dopamine neurons in rat ventral tegmental area. Eur J Pharmacol. 1993; 233:79-84. [PubMed: 8097162]

Guiard BP, El Mansari M, Blier P. Cross-talk between dopaminergic and noradrenergic systems in the rat ventral tegmental area, locus ceruleus, and dorsal hippocampus. Mol Pharmacol. 2008; 74:1463-1475. [PubMed: 18703671]

Hara E, Kubikova L, Hessler NA, Jarvis ED. Role of the midbrain dopaminergic system in modulation of vocal brain activation by social context. Eur J Neurosci. 2007; 25:3406-3416. [PubMed: 17553009]

Heimovics SA, Cornil CA, Ball GF, Riters LV. D1-like dopamine receptor density in nuclei involved in social behavior correlates with song in a context-dependent fashion in male European starlings. Neuroscience. 2009:962-973. [PubMed: 19356680]

Heimovics SA, Cornil CA, Ellis JMS, Ball GF, Riters LV. Seasonal and individual variation in singing behavior correlates with alpha 2-noradrenergic receptor density in brain regions implicated in song, sexual, and social behavior. Neuroscience. 2011

Heimovics SA, Riters LV. Immediate early gene activity in song control nuclei and brain areas regulating motivation relates positively to singing behavior during, but not outside of, a breeding context. J Neurobiol. 2005; 65:207-224. [PubMed: 16155901]

Heimovics SA, Riters LV. ZENK labeling within social behavior brain regions reveals breeding context-dependent patterns of neural activity associated with song in male European starlings (Sturnus vulgaris). Behav Brain Res. 2007; 176:333-343. [PubMed: 17113163]

Heimovics SA, Riters LV. Evidence that dopamine within motivation and song control brain regions regulates birdsong context-dependently. Physiol Behav. 2008; 95:258-266. [PubMed: 18619478]

Hessler NA, Doupe AJ. Social context modulates singing-related neural activity in the songbird forebrain. Nat Neurosci. 1999; 2:209-211. [PubMed: 10195211]

Hull EM, Bazzett TJ, Warner RK, Eaton RC, Thompson JT. Dopamine receptors in the ventral tegmental area modulate male sexual behavior in rats. Brain Res. 1990; 512:1-6. [PubMed: 2337797]

Jarvis ED, Scharff C, Grossman MR, Ramos JA, Nottebohm F. For whom the bird sings: contextdependent gene expression. Neuron. 1998; 21:775-788. [PubMed: 9808464]

Kilts CD, Breese GR, Mailman RB. Simultaneous quantification of dopamine, 5-hydroxytryptamine and four metabolically related compounds by means of reversed-phase high-performance liquid chromatography with electrochemical detection. J Chromatogr. 1981; 225:347-357. [PubMed: 7298770]

Kubikova L, Wada K, Jarvis ED. Dopamine receptors in a songbird brain. J Comp Neurol. 2010; 518:741-769. [PubMed: 20058221]

Leblois A, Wendel BJ, Perkel DJ. Striatal dopamine modulates basal ganglia output and regulates social context-dependent behavioral variability through D1 receptors. J Neurosci. 2010; 30:57305743. [PubMed: 20410125]

Lehner, PN. Handbook of Ethological Methods. Cambridge University Press; Cambridge: 1996.

Lewis JW, Ryan SM, Arnold AP, Butcher LL. Evidence for a catecholaminergic projection to area X in the zebra finch. J Comp Neurol. 1981; 196:347-354. [PubMed: 7217361]

Lynch KS, Diekamp B, Ball GF. Catecholaminergic cell groups and vocal communication in male songbirds. Physiol Behav. 2008; 93:870-876. [PubMed: 18191965]

Maney DL, Ball GF. Fos-like immunoreactivity in catecholaminergic brain nuclei after territorial behavior in free-living song sparrows. J Neurobiol. 2003; 56:163-170. [PubMed: 12838581]

Mello CV, Pinaud R, Ribeiro S. Noradrenergic system of the zebra finch brain: immunocytochemical study of dopamine-beta-hydroxylase. J Comp Neurol. 1998; 400:207-228. [PubMed: 9766400] 
Mello CV, Vicario DS, Clayton DF. Song presentation induces gene expression in the songbird forebrain. Proc Natl Acad Sci U S A. 1992; 89:6818-6822. [PubMed: 1495970]

Moore KE. Drug-induced changes in the efflux of dopamine and serotonin metabolites from the brains of freely moving rats. Ann N Y Acad Sci. 1986; 473:303-320. [PubMed: 2432822]

Nordeen, EJ.; Nordeen, KW. Circuits and cellular mechanisms of sensory acquisition. In: Ziegler, HP.; Marler, PR., editors. Neuroscience of Birdsong. Cambridge University Press; Cambridge: 2008. p. 256-270.

Panksepp, J.; Moskal, J. Dopamine and seeking: Subcortical reward systems and appetitive urges. In: Elliot, AJ., editor. Handbook of Approach and Avoidance Motivation. Taylor and Francis; New York: 2008. p. 67-88.

Pfaus JG, Damsma G, Wenkstern D, Fibiger HC. Sexual activity increases dopamine transmission in the nucleus accumbens and striatum of female rats. Brain Res. 1995; 693:21-30. [PubMed: 8653411]

Pinxten R, De Ridder E, Balthazart J, Eens M. Context-dependent effects of castration and testosterone treatment on song in male European starlings. Horm Behav. 2002; 42:307-318. [PubMed: 12460590]

Rauceo S, Harding CF, Maldonado A, Gaysinkaya L, Tulloch I, Rodriguez E. Dopaminergic modulation of reproductive behavior and activity in male zebra finches. Behav Brain Res. 2008; 187:133-139. [PubMed: 17945359]

Riters LV, Eens M, Pinxten R, Ball GF. Seasonal changes in the densities of alpha(2) noradrenergic receptors are inversely related to changes in testosterone and the volumes of song control nuclei in male European starlings. J Comp Neurol. 2002; 444:63-74. [PubMed: 11835182]

Riters LV, Eens M, Pinxten R, Duffy DL, Balthazart J, Ball GF. Seasonal changes in courtship song and the medial preoptic area in male European starlings (Sturnus vulgaris). Horm Behav. 2000; 38:250-261. [PubMed: 11104643]

Riters LV, Teague DP, Schroeder MB, Cummings SE. Vocal production in different social contexts relates to variation in immediate early gene immunoreactivity within and outside of the song control system. Behav Brain Res. 2004; 155:307-318. [PubMed: 15364491]

Salvante KG, Racke DM, Campbell CR, Sockman KW. Plasticity in singing effort and its relationship with monoamine metabolism in the songbird telencephalon. Dev Neurobiol. 2010; 70:41-57. [PubMed: 19899137]

Sasaki A, Sotnikova TD, Gainetdinov RR, Jarvis ED. Social context-dependent singing-regulated dopamine. J Neurosci. 2006; 26:9010-9014. [PubMed: 16943558]

Scharff C, Nottebohm F. A comparative study of the behavioral deficits following lesions of various parts of the zebra finch song system: implications for vocal learning. J Neurosci. 1991; 11:28962913. [PubMed: 1880555]

Schroeder MB, Riters LV. Pharmacological manipulations of dopamine and opioids have differential effects on sexually motivated song production in male European starlings. Physiology and Behavior. 2006; 88:575-584. [PubMed: 16784760]

Schultz W. Dopamine signals for reward value and risk: basic and recent data. Behavioral and Brain Functions. 2010; 6:24. [PubMed: 20416052]

Sockman KW, Salvante KG. The integration of song environment by catecholaminergic systems innervating the auditory telencephalon of adult female European starlings. Dev Neurobiol. 2008; 68:656-668. [PubMed: 18278799]

Stokes TM, Leonard CM, Nottebohm F. The telencephalon, diencephalon, and mesencephalon of the canary, Serinus canaria, in stereotaxic coordinates. J Comp Neurol. 1974; 156:337-374. [PubMed: 4609173]

Teramitsu I, Poopatanapong A, Torrisi S, White SA. Striatal FoxP2 is actively regulated during songbird sensorimotor learning. PLoS One. 2010; 5:e8548. [PubMed: 20062527]

Theunissen, FE.; Amin, N.; Shaevitz, S.; Woolley, SMN.; Fremouw, T.; Hauber, ME. Song selectivity and the songbird brain. In: Ziegler, HP.; Marler, PR., editors. Neuroscience of Birdsong. Cambridge University Press; Cambridge: 2008. p. 157-173.

Waterman SA, Harding CF. Neurotoxic effects of DSP-4 on the central noradrenergic system in male zebra finches. Behav Brain Res. 2008; 188:271-280. [PubMed: 18160108] 
Wild, MJ. Birdsong: Anatomical foundations and central mechanisms of sensorimotor integration. In: Ziegler, HP.; Marler, PR., editors. Neuroscience of Birdsong. Cambridge University Press; Cambridge: 2008. p. 136-152.

Wise RA. Forebrain substrates of reward and motivation. J Comp Neurol. 2005; 493:115-121. [PubMed: 16254990]

Yanagihara S, Hessler NA. Modulation of singing-related activity in the songbird ventral tegmental area by social context. Eur J Neurosci. 2006; 24:3619-3627. [PubMed: 17229110] 


\section{Research highlights}

- Individual male starlings increased (sexually motivated) or decreased (nonsexually motivated) song in response to a female

- Dopamine markers and norepinephrine in VTA and dopamine in area X correlated positively with sexually-motivated song

- Norepinephrine in area X correlated negatively with non-sexually-motivated song

- Dopamine markers in GCt correlated negatively with sexually-motivated song and positively with non-sexually-motivated song

- Individual differences in catecholamine activity in VTA, GCt, and area X may underlie individual differences in song 


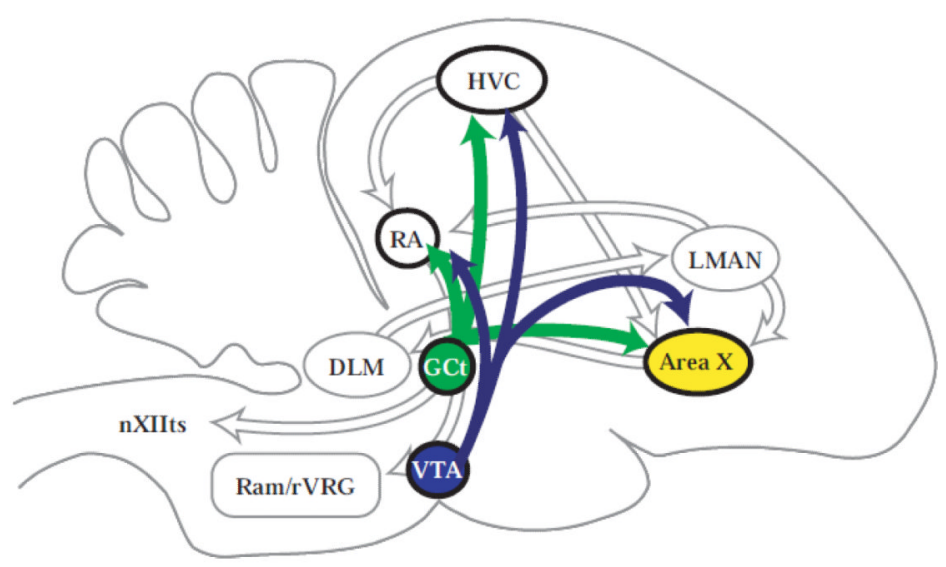

Figure 1.

Dopaminergic projections to the song control system. Sagittal schematic showing projections from the ventral tegmental area (VTA) and mesencephalic central gray (GCt) to area $\mathrm{X}$ and additional song control nuclei, HVC and the robust nucleus of the arcopallium (RA). Other abbreviations: LMAN, lateral portion of the magnocellular nucleus of the anterior nidopallium; DLM, medial portion of the dorsolateral nucleus of the anterior thalamus; Ram/rVRG, nucleus retroambigualis/rostral ventral respiratory group; nXIIts, tracheosyringial portion of the hypoglossal nucleus. 

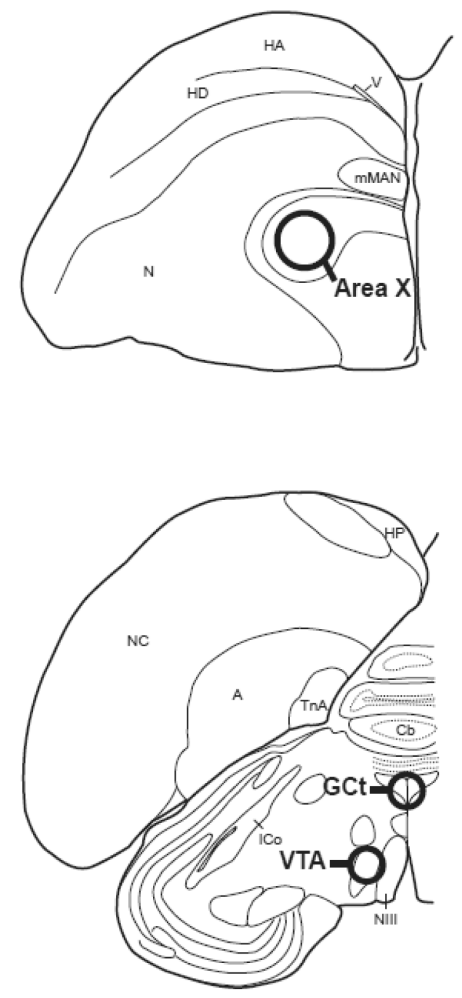

Figure 2.

Illustration of one coronal hemisphere of starling brain. Circles indicate approximate locations where sample corers were used to microdissect brain tissue from area X (panel A), GCt and VTA (panel B). Bilateral punches were taken from Area X and VTA. Single, centered punches were taken from GCt. Abbreviations: A, arcopallium; Cb, cerebellum; GCt, mesencephalic central gray; HA, apical part of the hyperpallium; HD, densocellular part of the hyperpallium; HP, hippocampus; ICo, nucleus intercollicularis; mMAN, medial magnocellular nucleus of the anterior nidopallium; NIII, third cranial nerve; N, nidopallium; NC, caudal nidopallium; TnA, nucleus taeniae of the amygdala; VTA, ventral tegmental area. 

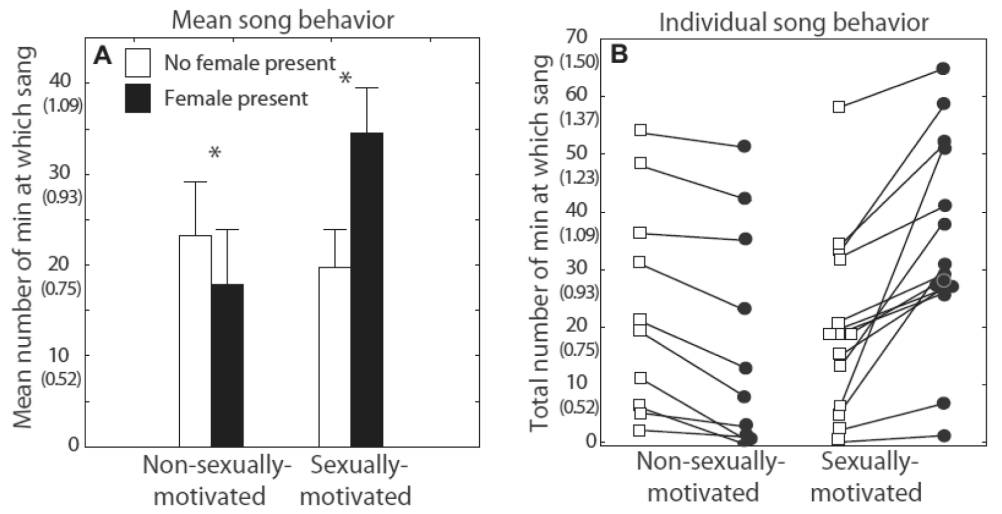

Figure 3.

A) Untransformed mean number of minutes + sem and B) the total number of minutes for each individual at which males in the non-sexually-motivated and sexually-motivated groups were singing when no female was present and when a female was present. The lines in panel B connect data points from single individuals. Untransformed data are presented in these figures to illustrate actual song data with the arcsine transformed values in parentheses below to aid in interpretation of transformed values in Figs 4 - 6 . Analyses were performed on arcsine transformed data as detailed in the methods. ${ }^{*}=$ significant posthoc results, $\mathrm{p}<$ 0.05 . 

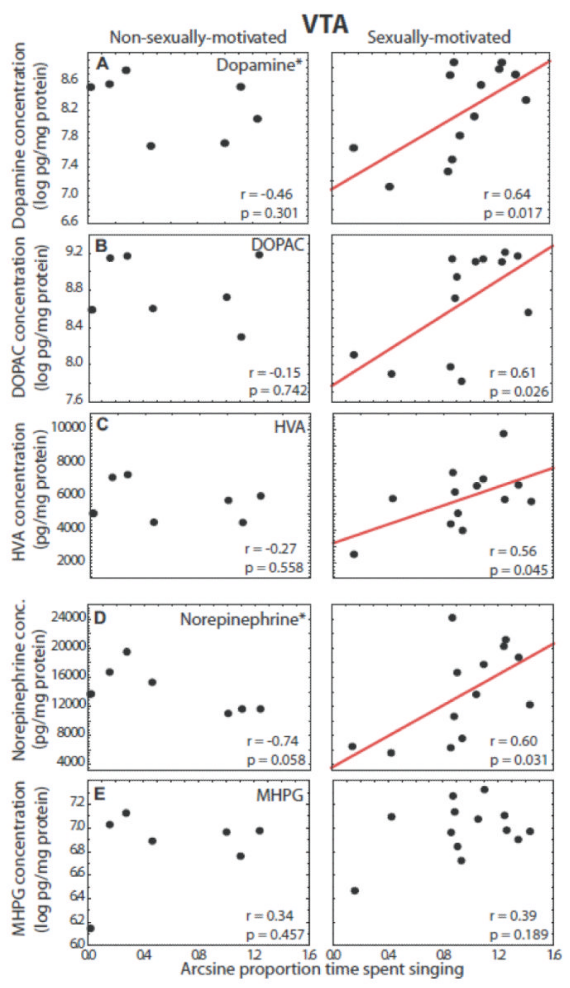

Figure 4.

Correlations between catecholamine markers in VTA and song. Scatterplots showing correlations between concentrations of dopamine markers (A - C) and norepinephrine markers ( $\mathrm{D}$ and $\mathrm{E}$ ) and individual variation in singing behavior in non-sexually-motivated (left column) and sexually-motivated males (right column). Each point represents one individual and the presence of a solid regression line indicates a significant linear correlation $(\mathrm{p}<0.05)$. * next to marker labels indicates that the slopes of the two correlations for a given marker differ significantly, $\mathrm{p}<0.05$. 

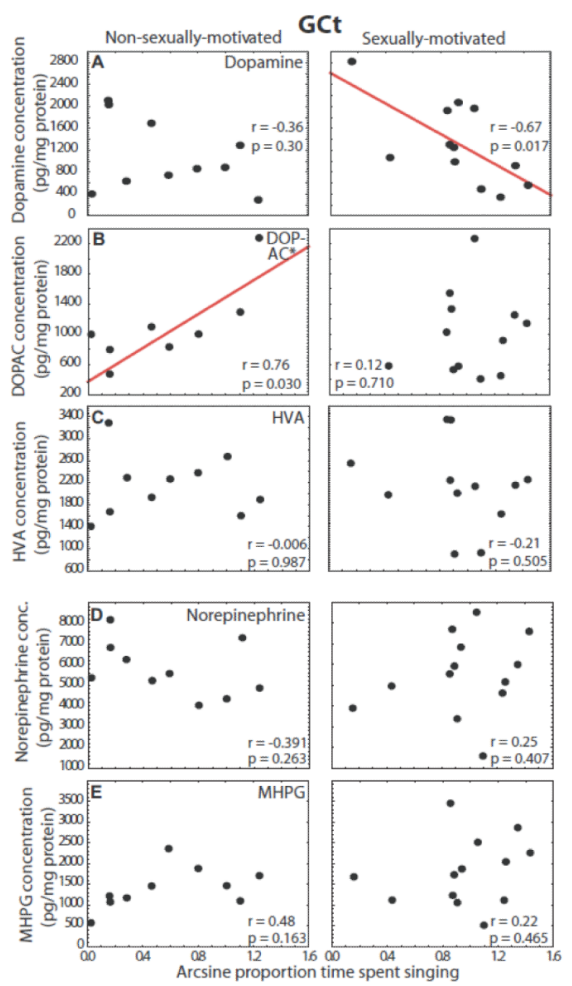

Figure 5.

Correlations between catecholamine markers in GCt and song. Scatterplots showing correlations between concentrations of dopamine markers (A - C) and norepinephrine markers ( $\mathrm{D}$ and $\mathrm{E}$ ) and individual variation in singing behavior in non-sexually-motivated (left column) and sexually-motivated males (right column). Each point represents one individual and the presence of a solid regression line indicates a significant linear correlation $(\mathrm{p}<0.05)$. * next to marker labels indicates that the slopes of the two correlations for a given marker differ significantly, $\mathrm{p}<0.05$. 

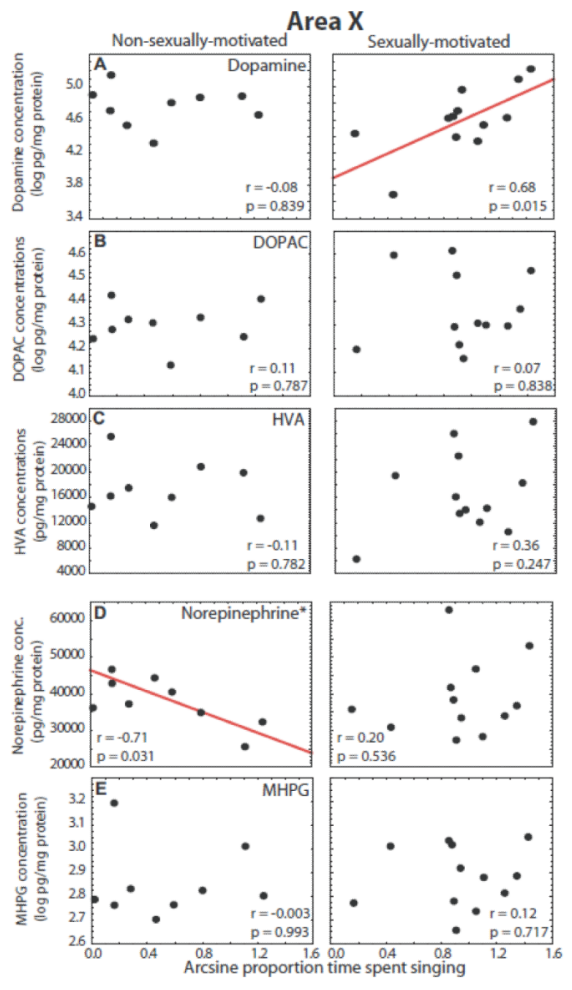

Figure 6.

Correlations between catecholamine markers in area $\mathrm{X}$ and song. Scatterplots showing correlations between concentrations of dopamine markers (A - C) and norepinephrine markers ( $\mathrm{D}$ and $\mathrm{E}$ ) and individual variation in singing behavior in non-sexually-motivated (left column) and sexually-motivated males (right column). Each point represents one individual and the presence of a solid regression line indicates a significant linear correlation $(\mathrm{p}<0.05)$. * next to marker labels indicates that the slopes of the two correlations for a given marker differ significantly, $\mathrm{p}<0.05$. 


\section{Table 1}

Contributions of norepinephrine (NE) markers to dopamine (DA) markers in VTA and GCt based on multiple regression analyses

\begin{tabular}{|c|c|c|c|c|}
\hline DA marker (DV) & contributors & beta & beta s.e. & p value \\
\hline \multicolumn{5}{|l|}{ VTA dopamine } \\
\hline $\operatorname{adj} R^{2}=0.76, n=20, p=0.000002$ & $\begin{array}{l}\text { VTA NE } \\
\text { VTA MHPG }\end{array}$ & $\begin{array}{r}0.96 \\
-0.31\end{array}$ & $\begin{array}{l}0.12 \\
0.12\end{array}$ & $\begin{array}{l}0.000 \\
0.019\end{array}$ \\
\hline \multicolumn{5}{|l|}{ VIA DOPAC } \\
\hline $\operatorname{adj} R^{2}=0.70, n=20, p=0.000003$ & VTA NE & 0.84 & 0.13 & 0.000 \\
\hline \multicolumn{5}{|l|}{$V I A H V A$} \\
\hline $\operatorname{adj} R^{2}=0.60, n=20, p=0.0002$ & $\begin{array}{l}\text { VTA NE } \\
\text { VTA MHPG }\end{array}$ & $\begin{array}{l}0.51 \\
0.46\end{array}$ & $\begin{array}{l}0.16 \\
0.16\end{array}$ & $\begin{array}{l}0.005 \\
0.009\end{array}$ \\
\hline \multicolumn{5}{|l|}{ GCt dopamine } \\
\hline $\operatorname{adj} R^{2}=0.25, n=21, p=0.012$ & GCt NE & 0.54 & 0.19 & 0.012 \\
\hline \multicolumn{5}{|l|}{ GCt DOPAC } \\
\hline $\operatorname{adj} R^{2}=0.34, n=19, p=0.013$ & GCt NE & 0.50 & 0.20 & 0.022 \\
\hline \multicolumn{5}{|l|}{$G C t H V A$} \\
\hline $\operatorname{adj} R^{2}=0.28, n=22, p=0.016$ & GCt MHPG & 0.46 & 0.19 & 0.027 \\
\hline
\end{tabular}




\section{Table 2}

Contribution of dopamine (DA) in VTA and GCt to markers in area X based on multiple regression analyses

\begin{tabular}{lllll}
\hline Marker $(\mathrm{DV})$ & contributors & beta & beta s.e. & p value \\
\hline Area $X$ dopamine & & & & \\
adj $\mathrm{R}^{2}=0,32, \mathrm{n}=16, \mathrm{p}=0.013$ & VTA DA & 0.60 & 0.21 & 0.013 \\
Area $X$ DOPAC & & & & \\
adj $\mathrm{R}^{2}=0.49, \mathrm{n}=16, \mathrm{p}=0.005$ & VTA DA & -0.79 & 0.21 & 0.002 \\
& GCt DA & -0.59 & 0.21 & 0.013 \\
\hline
\end{tabular}

